\title{
Urban Adaptation to Climate Change Plans and Policies - the Conceptual Framework of a Methodological Approach
}

\author{
Julianna Kiełkowska', Katarzyna Tokarczyk-Dorociak², Jan Kazak, \\ Szymon Szewrański', Joost van Hoof ${ }^{1,3}$
}

1 Wrocław University of Environmental and Life Sciences, Department of Spatial Economy, Grunwaldzka st. 55, 50-357 Wrocław, Poland

2 Wrocław University of Environmental and Life Sciences, Institute of Landscape Architecture, Grunwaldzka st.55, 50-357 Wrocław, Poland

3 The Hague University of Applied Sciences, Faculty of Social Work and Education, Johanna Westerdijkplein 75, 2521 EN The Hague, The Netherlands

* Corresponding author's e-mail: jan.kazak@upwr.edu.pl

\begin{abstract}
The adaptation of urbanised areas to climate change is currently one of the key challenges in the domain of urban policy. The diversity of environmental determinants requires the formulation of individual plans dedicated to the most significant local issues. This article serves as a methodic proposition for the stage of retrieving data (with the PESTEL and the Delphi method), systemic diagnosis (evaluation of risk and susceptibility), prognosis (goal trees, goal intensity map) and the formulation of urban adaptation plans. The suggested solution complies with the Polish guidelines for establishing adaptation plans. The proposed methodological approach guarantees the participation of various groups of stakeholders in the process of working on urban adaptation plans, which is in accordance with the current tendencies to strengthen the role of public participation in spatial management.
\end{abstract}

Keywords: urban adaptation plan, climate change, environmental management system, resilience, sustainable urbanization

\section{INTRODUCTION}

Regardless of the possible opinions on the subject of the reasons behind climate change the results of the changes it involves are currently apparent in nearly every single one of the world's communities. Additionally, their effects have been accumulating and intensifying in the last few decades (Kurek, 2011). This results in the increasingly common and severe weather anomalies which lead to spatial, economic and social transformations, most devastatingly felt in developing states. In the long-term context their consequences will be experienced in every place on Earth (Walsh and Wuebbles, 2014). The influence of these changes might prove unfavourable for the development of many countries, and their consequences - if no response tools are introduced and utilised - may lead to extreme results
(Ministry of the Environment, 2013). The process of increasing adaptation capacity, which would lower the cost of future climate change (Kemfert, 2005) and lead to an increase in the quality of life in cities (Przybyła et el., 2014), has to be initiated in order to minimise the unfavourable impact of the related dangers and to make use of any available opportunities. Under Polish conditions, the urbanisation processes which intensified in the 1990s (Foryś and Putek-Szelag, 2014) contribute to increasing the vulnerability of the socioeconomic system to local climate change and the status of available environmental resources (Szewrański et al., 2017).

Aiming at implementing the Nairobi Work Programme(UNFCCC 2012c) the European Commission published on April 1, 2009 a white paper titled: Adapting to climate change: towards a European Framework for Action, COM(2009)147, 
with an established set of EU efforts towards preparing an elaborate EU adaptation strategy. This launched a wide discussion in the expert circles, which resulted in the creation of a complex EU strategy for climate change adaptation, published in April 2013. The strategy is aimed at improving the "resistance" of member states and their communities against current and expected climate changes, with special emphasis on making preparations for extreme weather phenomena and decreasing the social and economic costs they involve. Due to various natural determinants and variations in the intensity of the changes in each region of Europe, it is required to look for solutions adjusted to regional determinants. This is why the EU adaptation strategy entails the mobilisation of member states towards formulating national adaptation strategies. Acknowledged in the strategy is the need to increase the resistance of key branches of the economy, utilising lowcost and flexible solutions and conducting further research, exchanging knowledge and good practices. The European Commission means to support these actions through properly coordinating and popularising them, as well as including the provisions of the adaptation strategy in key EU policies (Świąder et al., 2016). One example of coordination and inclusion into other union policies is the connection between the spending of European funds and the need for a member state to establish a strategy for adapting to climate change (so-called ex ante conditionalities).

In Poland, the outcome of the EU recommendations outlined above is the Polish National Strategy for Adaptation to Climate Change with the perspective by 2030 (SPA2020). It is a key document devoted to climate change adaptation under Polish conditions. One of its priorities is to introduce Urban Adaptation Plans (UAP), created with the goal of coordinating the delivery of work in this area (Ministry of the Environment, 2014). One of the key aspects which should be included in the UAP is the problem of managing rainwater. The proposed solutions may address such issues as e.g. the capacity of storing water in the soil (Biniak-Pieróg, 2014; Olszewska and Nowicka, 2015), utilising technologies aimed at water conditioning (Pawęska and Bawiec, 2017) or increasing the role of green (Kazak et al., 2016) and blue (Tokarczyk-Dociaciak et al., 2017) infrastructure.

Adaptation may be planned (pre-emptive) or autonomic (reactive). The first allows for preparing the basis for accepting changes and involves increasing the flexibility and the adaptation capacity of the system, developing social awareness and responsibility, as well as stimulating readiness for action. It is introduced before the effects become apparent, when a future occurrence is inevitable and expected. Reactive adaptation allows to react to changes after they have already occurred, by changing the pursued policy or adapting available tools to the effects (Leszczyńska, 2013).

Choosing the direction of climate change adaptation is a typical example of the decision-making under uncertainty process (DMUU). A DMUU process requires a deep-level identification of the capacities of implementing an adaptation policy and makes use of scenario methods in order to ensure flexibility in decision-making (Kazak et al., 2017). One example of this approach involves the process of choosing an adaptation scenario regarding the changes in the water economy for the Phoenix metropolitan area (Gober et al., 2016). It includes the possible fluctuations in the water resources due to climate conditions and changes in the management system. Research has shown that by choosing the proper adaptation policy it is possible to fully prepare a region for intense droughts. Adaptation policies remain a relatively new idea, which is why the approaches they involve contain certain imperfections. An overview of practices aimed at adaptation in 74 cities indicated that the fundamental flaws include: focusing exclusively on the protection of infrastructural goods to the detriment of health-related and social values (in the case of 142 out of 997 implemented initiatives), a lack of a holistic perspective on the adaptation process and targeting the unidirectional impact of climate change consequences (97\%), omitting the planning of monitoring and evaluation (51\%) and the lack of any opportunity at social participation (52\%) (Araos et al., 2016). In an age of growing available data resources the optimisation of the decision-making process with regard to climate change adaptation is possible through the integration and use of geographic information systems and business intelligence systems (Szewrański et al., 2017).

The lack of local participants in the process eliminates the possibility for a wider perspective on the adaptation capacities resulting from local determinants (Sarzynski, 2015). An increasing number of cities notices the need for adaptation as early as at the stage of creating policies, yet also apparent is the lack of developed tools for planning (van de Ven et al., 2016). To this end it 
is important to involve local stakeholders in the process, providing them with the required knowledge (the ClimateApp project stands as a good example of this) and tools along with instructions on designing and implementing ideas. One example of this is the Adaptation Support Tool, which helps establish adaptation capacity (including the matter of collecting knowledge regarding local determinants), define local consequences and susceptibility to climate change (through analysing the source of occurring problems and indicating prevention methods) and establishing priorities and implementation methods (through confronting ideas with real possibility).

Both the EU adaptation strategy and the SPA 2020 include an indication of cities as areas which may be especially vulnerable to the consequences of climate change. This is related to their key contribution in generating GDP and innovation (which is why they are referred to as the "locomotives of development"), as well as the fact that the majority of European citizens live in cities (in Poland this currently is $60 \%$ of the population). The SPA 2020 includes the recommendation for cities with populations above 100000 citizens to establish urban adaptation plans until 2020, which would include both an analysis of threats as well as propositions of adaptation actions. The Ministry of the Environment, as the authority responsible for implementing the national adaptation strategy, introduced its Adaptation manual for cities, which includes practical instructions for the process of preparing urban adaptation plans (Ministry of the Environment, 2014). The manual includes recommendations regarding the process of formulating an urban adaptation plan, with special focus on each stage and the analyses required for implementation (Fig. 1).

The guidelines include instructions and essential issues which need to be taken into account, as well as explanations of the difference between each phenomenon (vulnerability, susceptibility, risk, the adaptation potential of a city). However, they do not include any indication regarding specific methods and tools required to perform a given analysis or deliberation. In practice, the
UAP contractor in Poland should act in accordance with the guidelines included in the manual. The authority ordering the UAP, when choosing its contractor, may precisely specify their requirements in a detailed description of the subject of public procurement. Because of this, the UAP has to be formulated in accordance with the guidelines of the manual, but the methods and tools used for analyses might include other known and proven solutions.

\section{AIM AND METHODS}

Establishing climate change adaptation solutions in cities is directly related to the problems of an optimised management of space. The aim of this article is to establish an index of methods and tools which allow for the creation of an objective adaptation policy. This will involve descriptions of techniques used for data retrieval (PESTEL and the Delphi technique), systemic diagnosis (evaluation of risk and susceptibility), prognosis (goal trees, goal intensity map) and formulation of urban adaptation plans. In order for a more coherent representation of the proposed methodology, selected matrices have been complemented with an example scenario making use of a hypothetical situation.

A set of inventive methods within the association technique have been used in the realisation process of this paper. The methods utilised included: analogous transfer method (allowing to transfer principles between fields), the concept transfer method (allowing to transfer concepts along with redefining them), general statement method (involving the use of such statements from other fields which retain universal truth for a long period of time).

\section{RESULTS}

Creating an UAP requires the identification of the impact of the surroundings on the situation of a unit and its internal susceptibility, risk and

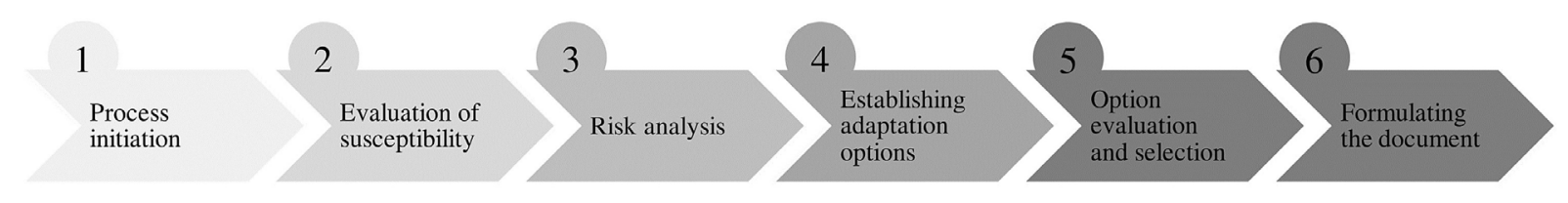

Figure 1. A framework schedule for preparing an Urban Adaptation Plan [Ministry of the Environment, 2014] 
adaptation potential, and later the establishing of adaptation goals. UAPs should also indicate the method of their implementation and monitoring. In practice, the process of creating, implementing and evaluating its effects becomes circular, as the basis for correcting the document is automatically supplied by observing the results of the adaptation (Obłój, 2001).

The entirety of actions needs to include the organisation of the process of formulating the plandefining the participants (the Programme Council, the Working Committee and Task Groups), work organisations (establishing the production process procedure, selecting a method for teamwork) and managing the strategic prognosis stage (foresight). Foresight may be defined as futuring and planning (Fig. 2). The first term refers to the identification and evaluation process for possible future events, while planning additionally involves establishing a set of initial decisions based on prior futuring (Litewka, 2010).

The below model (Fig. 3) represents the established UAP creation model. Before beginning the process, one has to conduct a diagnosis, i.e. study the features of the unit, the previous and possible consequences of climate change and their effects; interpreting the relations between them will allow to distinguish priority effect zones. Through prognosis, i.e. formulating suit- able questions and associations with the use of an adjusted methodology one can collect a pool of potential goals, which then needs to be narrowed down and elaborated upon in the process of strategic programming. This will result in the establishing of adaptation directions along with principles for implementation and monitoring. This approach will allow for the creation of a complete UAP, the essence of which can be represented in the form of aim and action cards.

\section{THE METHODOLOGY OF RETRIEVING ENTRY DATA}

The required information needs to be collected in order to perform a diagnosis. This requires an analysis of the type of the unit and its surroundings. The PESTEL 635 and Delphi technique described below are recommended for use at the stage of data retrieval.

\section{PESTEL 635}

The PESTEL (Political, Economic, Social, Technological, Environmental, Legal) structure may be used to collect data in an ordered manner. Open workshops for task groups and other participants are considered here to be its most effective form. The authors recommend collect-



Figure 2. Work schedule within the framework of the foresight process [Voros, 2008] 


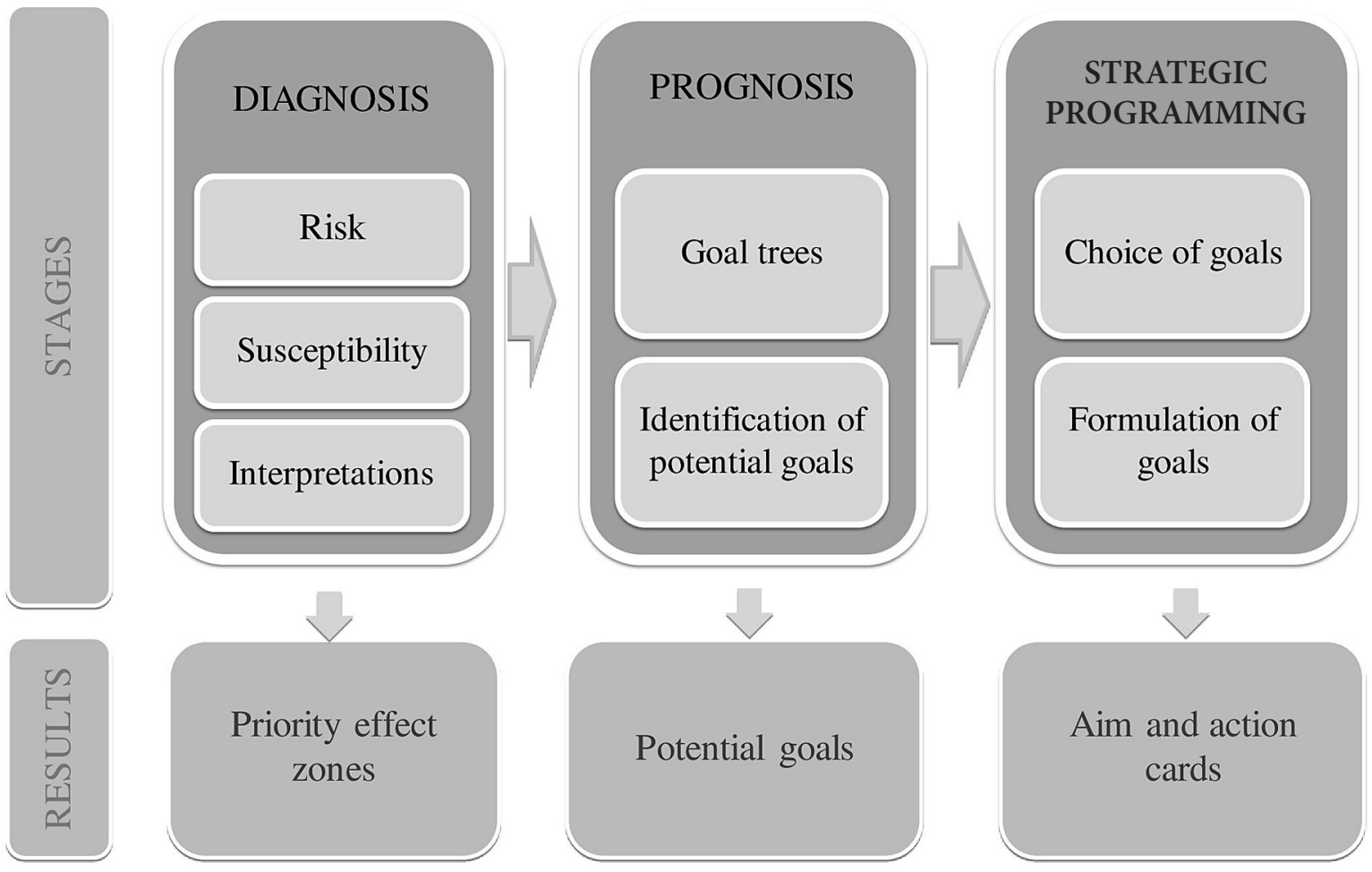

Figure 3. The proposed UAP document creation model

ing the data in a manner which will save time and utilise the potential of each stakeholder. One possible option is the 635 technique, which involves retrieving 3 answers from each participant of a 6-person group within 5 minutes. This technique can be analogously modified by adjusting the time and the number of answers and people in groups (Przybyło, 2011). Its strong point is that it provides a significant number of solutions with a relatively low expenditure of time and effort.

\section{The Delphi technique}

The Delphi technique is a valuable option when looking to ensure the freedom of comparing information retrieved from external subjects, as well as a comfortable manner of cooperation. The technique involves creating a universal answer sheet and involving the experts in filling it out and controlling the results. The method uses hypothetical assumptions regarding the potential consequences of climate change. The form should be available for editing to experts in the domain of climate change and from related fields. Each participant completes the sheet according to their own knowledge regarding the likely changes in each specified component, as well as a quantitative evaluation of the degree of intensity of each phenomenon.
Retrieving data from independent sources allows for employing a diagnostic-functional approach, i.e. for combining the descriptiveimproving method (the diagnostic method) with the pattern-functional method (the prognostic method). Blending these two organisational methods allows for achieving independent results (Molasy, 2016).

\section{THE METHODOLOGY OF SYSTEMIC DIAGNOSIS}

Owing to the high level of complexity and connections between the many elements involved, further diagnosis has been suggested in the form of a systemic analysis, which takes into account the characteristic traits of the climate and the significance of the consequences resulting from climate change; it involves determining the internal structure of an element and as many systemic interactions with other factors as possible. This results in a set of parameters with a variable interaction force. The evaluation in its initial version is represented in a qualitative manner, but for the purpose of a more coherent interpretation of the results the parameters are translated into quantitative values. A set of comparable indicators has 
been established through mathematical calculation (Molasy, 2016; Kazak et al., 2017). Predicting the future may be described as a process of verifying prognoses with regard to past events of analogous sources of origin and features.

\section{Risk}

It is important in the process of formulating a UAP to estimate the risk of climate change consequences. Risk estimation involves the analysis of climatic events which have occurred in the past, after taking into account existing threats. The result of a risk analysis is a list of past events considered negative with regard to environmental change, danger to the community, financial loss and the disruption of spatial order and sustainable development, along with a description of undertaken actions and a valorisation of their effects in accordance with an evaluation of their spatial range, duration, reversibility and degree of damage.

The model matrix (Table 1) included above represents the analysis of a hypothetical event from the past, i.e. a period of drought observed in the town of Cieszyn. It has been indicated, based on meteorological, climatic, spatial and other analyses that the event was caused by a decrease in yearly precipitation. Other data included the location and date of the event as well as its duration. Information regarding undertaken prevention efforts will prove helpful in future action (no such efforts have been attempted in the example). Included is a detailed analysis of the consequences of the drought, i.e. a decrease in agricultural harvest, which impact the town's economy. For the sake of clarity it is helpful to point out ac- tions which had been undertaken to mitigate the decrease in harvest and to repair the situation.

The 4 final stages of the evaluation will directly serve the calculation of the risk significance rate for the consequences. The decrease in agricultural harvest has first been evaluated in a descriptive manner, as impacting the local level (within the town's limits) and the supra-local level (having a direct or indirect impact beyond the administrative borders of the town, in the region of Cieszyn Silesia). The duration refers not only to the period of the harvest itself, but also that of the effects experienced in the form of reduced resources and income. This consequence has been evaluated as irreversible, though it may be possible to prepare specific adaptation efforts in the next season. The damages resulting from the drought have made functioning harder, depriving the community and town of income and decreasing food resources etc. These 4 evaluations have been translated into a quantitative form with the use of a conversion table (Table 2).

The resulting risk significance rate for the drastically decreased agricultural harvest has been calculated to be 360 points.

In the case of drought, more consequences can be assigned, whose average of risk significance rate will determine the risk significance rate of the event. Analogously, the risk significance rate of the cause of the event is determined using the average of the event's risk significance rate.

\section{Susceptibility}

The evaluation of the susceptibility to climate change consequences is the next element analysed

Table 1. Past analysis matrix using the example of drought in Cieszyn

\begin{tabular}{|c|c|c|}
\hline \multicolumn{2}{|c|}{ Event } & Drought \\
\hline \multicolumn{2}{|l|}{ Event cause } & Decrease in precipitation \\
\hline \multicolumn{2}{|l|}{ Place of event } & Cieszyn \\
\hline \multicolumn{2}{|c|}{ Commencement date } & Beginning of June, 2015 \\
\hline \multicolumn{2}{|l|}{ Duration } & 3 months \\
\hline \multicolumn{2}{|l|}{ Prevention } & $\begin{array}{l}\text { The possibility of a drought had been taken into account. No prevention efforts had } \\
\text { been undertaken }\end{array}$ \\
\hline \multicolumn{2}{|l|}{ Consequences } & Decrease in agricultural harvest \\
\hline \multicolumn{2}{|l|}{ Area of effect } & Economy \\
\hline \multicolumn{2}{|l|}{ Mitigation } & $\begin{array}{l}\text { Expected. No prevention efforts had been undertaken due to large financial } \\
\text { expenditure }\end{array}$ \\
\hline \multicolumn{2}{|l|}{ Repair } & A compensation claim has been filed for \\
\hline \multirow{4}{*}{$\begin{array}{l}\text { Consequence } \\
\text { type }\end{array}$} & Scope & Local and supra-local \\
\hline & Duration & 8-12 months \\
\hline & Reversibility & Irreversible \\
\hline & Degree of damage & Damage that hinders functioning \\
\hline
\end{tabular}


Table 2. List of answers for evaluating the consequence type along with their quantitative equivalent

\begin{tabular}{|c|c|c|c|}
\hline & Specification & Qualitative evaluation & Quantitative evaluation \\
\hline \multirow{21}{*}{ 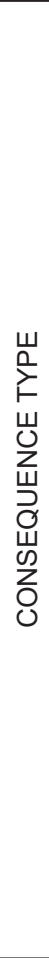 } & \multirow{3}{*}{ Scope } & Local & 1 \\
\hline & & Supra-local & 2 \\
\hline & & Local and supra-local & 3 \\
\hline & \multirow{9}{*}{ Duration } & 1 day & 0.5 \\
\hline & & 2-7 days & 1 \\
\hline & & 2-4 weeks & 2 \\
\hline & & 2-4 months & 3 \\
\hline & & 4-8 months & 3.5 \\
\hline & & $8-12$ months & 4 \\
\hline & & $2-5$ years & 6 \\
\hline & & $5-10$ years & 8 \\
\hline & & Over 10 years & 10 \\
\hline & \multirow{4}{*}{ Reversibility } & Easily reversible & 0.5 \\
\hline & & Reversible & 1 \\
\hline & & Difficult to reverse & 5 \\
\hline & & Irreversible & 10 \\
\hline & \multirow{5}{*}{ Degree of damage } & Minor damage & 1 \\
\hline & & Visible damage & 2 \\
\hline & & Damage that hinders functioning & 3 \\
\hline & & Damage that makes functioning impossible & 4 \\
\hline & & $\begin{array}{l}\text { Damage that makes functioning impossible and is a threat to human } \\
\text { life and health }\end{array}$ & 5 \\
\hline
\end{tabular}

in the process of creating a UAP. Susceptibility is defined here as the result of the interaction between the local consequences of climate change and its existing traits. The evaluation of susceptibility serves to indicate areas which require or may in the future require efforts in the domain of climate change adaptation and to allow the identification of priorities. Creating a relation matrix will prove valuable in order to ensure the analysis of the highest possible number of combinations.

A relation matrix is one of the tools used for conducting an evaluation of susceptibility. It adheres to the principles of a SWOT/TOWS matrix. The possible changes in climate, indicated at the stage of data retrieval, cannot be unambiguously identified as dangers or possibilities. In order to do so, it is necessary to predict their potential in-

Table 3. Interaction force and sense evaluation scale for susceptibility

\begin{tabular}{|c|l|}
\hline 3 & Exceptionally favourable relation \\
\hline 2 & Highly favourable relation \\
\hline 1 & Favourable relation \\
\hline 0 & No relation \\
\hline-1 & Unfavourable relation \\
\hline-2 & Highly unfavourable relation \\
\hline-3 & Exceptionally unfavourable relation \\
\hline
\end{tabular}

teractions with existing factors, which will aid their identification as favourable or unfavourable.

The relation matrix (Table 4) may serve to conduct an evaluation of the interactions between the consequences of climate changes and the traits of an area. It follows the order indicated in the table: the first part involves the interaction of strengths and weaknesses on the possible consequences of climate change; the second part describes the reverse. Fields in the matrix marked (-) will include a quantitative evaluation in accordance with the $<-3 ; 3>$ scale (see: Table 3 ).

It has been concluded in the examples described above that implementing retention plans may favourably $(+3)$ influence the drought through collecting water resources, while the drought may unfavourably (-1) influence the stage of formulating the retention policy, introducing the need to update the diagnosis and documentation. The remaining interactions have been evaluated analogously. After the evaluation is complete one may begin calculating the indicators required for further work-these are described below.

Interaction force is the sum of all absolute values for each column or line respectively. It indicates the effect strength, but does not take into account the type of the factor, i.e. whether 
Table 4. Relation matrix model using a hypothetical example

\begin{tabular}{|c|c|c|c|c|c|c|c|c|}
\hline \multicolumn{3}{|c|}{ Possible climate change consequences } & \multirow{2}{*}{ Drought } & \multirow{2}{*}{$\begin{array}{c}\begin{array}{c}\text { Heat } \\
\text { waves }\end{array} \\
1\end{array}$} & \multirow{2}{*}{$\begin{array}{c}\begin{array}{c}\text { Force of } \\
\text { interaction }\end{array} \\
4\end{array}$} & \multirow{2}{*}{$\begin{array}{c}\begin{array}{c}\text { Sense of } \\
\text { interaction }\end{array} \\
4\end{array}$} & \multirow{2}{*}{$\begin{array}{c}\begin{array}{c}\text { Average } \\
\text { favourability } \\
\text { value }\end{array} \\
2\end{array}$} & \multirow{2}{*}{$\begin{array}{c}\text { Average } \\
\begin{array}{c}\text { unfavourability } \\
\text { value }\end{array} \\
0\end{array}$} \\
\hline \multirow{6}{*}{ 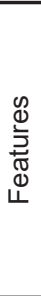 } & Politics & $\begin{array}{l}\text { Implementation of retention } \\
\text { plans }\end{array}$ & & & & & & \\
\hline & Economy & Traditional agriculture & -1 & 0 & 1 & -1 & 0 & -0.5 \\
\hline & Community & - & - & - & - & - & - & - \\
\hline & Technology & - & - & - & - & - & - & - \\
\hline & Ecology & - & - & - & - & - & - & - \\
\hline & Legislation & - & - & - & - & - & - & - \\
\hline \multirow{6}{*}{ 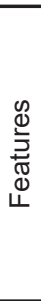 } & Politics & $\begin{array}{l}\text { Implementation of retention } \\
\text { plans }\end{array}$ & -1 & 0 & - & - & - & - \\
\hline & Economy & Traditional agriculture & -3 & -2 & - & - & - & - \\
\hline & Community & - & - & - & - & - & - & - \\
\hline & Technology & - & - & - & - & - & - & - \\
\hline & Ecology & - & - & - & - & - & - & - \\
\hline & Legislation & - & - & - & - & - & - & - \\
\hline & & Force of interaction & 4 & 2 & - & - & - & - \\
\hline & & Sense of interaction & -4 & -2 & - & - & - & - \\
\hline & & Average favourability value & 0 & 0 & - & - & - & - \\
\hline & & $\begin{array}{l}\text { Average unfavourability } \\
\text { value }\end{array}$ & -2 & -1 & - & - & - & - \\
\hline
\end{tabular}

it is involved in positive or negative interactions. The scale is dependent on the amount of strengths and weaknesses and the possible consequences of climate change.

Interaction sense is the sum of all values for each column or line respectively. It allows to determine the influence of the variable in a favourable (positive) or unfavourable (negative) manner. This distinction allows to define the consequences of climate change as opportunities or threats (in the above example both the drought and the heat waves are considered threats), while features may be defined as strengths and weaknesses. The scale is dependent on the number of strengths and weaknesses and the possible consequences of climate change.

The average favourability value for each factor is the arithmetic mean value calculated exclusively from favourable effects (positive evaluation). While the interaction sense involved the predominance of favourable or unfavourable effects, the average favourability value indicates the positive force of a given factor - its strength, weakness or possible consequences of climate change.

The average unfavourability value for each factor is the arithmetic mean value calculated exclusively from unfavourable effect (negative evaluation). It is a type of data analogous to the average favourability value.

\section{Interpretations}

The essential actions need to be planned in order to enable the realisation of goals. This in turn requires an evaluation of priorities. This is achieved through the use of: the average favourability value for evaluating future possibilities, and the threat value for potential future threats respectively. The threat value is the risk significance rate multiplied by the mean value of unfavourability; the value fits the range of $(0 ;-4500>$. This option may prove useful with regard to the number of events (e.g. $10 \%$ of threats with the highest threat value) or assigning priority to threats and possibilities according to a precise record of mean favourability and threat values based on a set of formulated ranges. This requires the creation of a collective matrix with results from the previous two analyses (Table 5). The factors with the highest priority will be used at further stages.

\section{THE PROGNOSIS METHOD}

Priority threats indicate the most urgent consequences of climate change, while high-level possibilities determine the direction for adaptation undertaken with the aim of utilising the best possible strengths or mitigating weaknesses. The inventive method, i.e. the forced associations technique, involving the creation of goal trees, 
Table 5. A model collective interpretation matrix using an example

\begin{tabular}{|l|l|c|c|c|c|}
\hline \multicolumn{2}{|c|}{ Factor } & $\begin{array}{c}\text { Mean favourability } \\
\text { value }\end{array}$ & $\begin{array}{c}\text { Mean } \\
\text { unfavourability } \\
\text { value }\end{array}$ & $\begin{array}{c}\text { Risk } \\
\text { significance } \\
\text { rate }\end{array}$ & Threat value \\
\hline Strengths & $\begin{array}{l}\text { Implementation of retention } \\
\text { plans }\end{array}$ & 2 & 0 & - & - \\
\hline Weaknesses & Traditional agriculture & 0 & -0.5 & - & - \\
\hline \multirow{2}{*}{ Future threats } & Drought & 0 & -2 & 360 & -720 \\
\cline { 2 - 6 } & Heat waves & 0 & -1 & 100 & -100 \\
\hline
\end{tabular}

should be chosen in order to elaborate on these issues and establish the development direction of the unit in new surroundings. This tool allows for the use of the diagnostic-functional approach. With the diagnostic method it is possible to delineate development patterns of existing strengths and advantages in a manner which will bring future benefits. The prognostic method will in turn allow to identify the directions for the realisation of a designed perfect vision, which in this case is the opposite of the diagnosed consequences of the events.

The creative problem solution method will prove helpful in deliberations on possible solutions. The initial stage involves collecting answers which have already been observed in reallife and may be a good choice for an issue under discussion. This is achieved through an analysis of undertaken efforts detailed during risk evaluation, and drawing examples from cities with similar problems. Once the issue is exhausted it might prove helpful to turn to ideas less analogous to the problem in question.

\section{The goal tree - the prognostic method}

Formulating a goal tree (Fig. 4) involves transforming event consequences in such a way, as to represent them as positive goals which are to be pursued (Trocki, 2012).

Let it be assumed that long-term droughts are considered the priority threat for a given city. The use of the results from risk analysis reveals an analogous threat which has already occurred there. The goal tree is created using the event consequences with the highest risk value for the consequence. The following example revolves around "unprofitable agriculture."

1. Transforming the negative results of an event in positive action goals

a) We want agriculture to continue to provide profit. This is the positive goal.

2. We establish the opportunities for changes which will allow the above goal to be achieved. b) We choose a change in crops, e.g. introducing corn resistant to drought.

Such postulates will most likely involve adaptation through transformation.

\section{Goal tree - the diagnostic method}

Positive interactions have also been provided, yet there is no indication as to the details of their effects. This is why the following goal tree (Fig. 5) is created using the diagnostic approach.

The opportunities that are chosen are retrieved from the highest priority group. This is followed by the identification of the strongest interactions from the relation matrix. The example uses the opportunity of heat waves and the advantage of water recreation areas. The goal tree will make it possible to order and develop the ideas for using this situation. The majority of guidelines will involve actions of gradual adaptation and confrontation.

\section{THE METHODOLOGY OF STRATEGIC PROGRAMMING}

By conducting prior analyses and specifying a set of solutions it is possible to formulate the complete document. This requires the selection of goals for realisation and the formulation of a hierarchical strategy of directions, goals and tasks.

Choosing directions, goals and tasks which will serve as guidelines for years of future work is a difficult stage. Decision-making in the case of adaptation plans and their systemic relations is usually a combination of deliberation, feeling, experience, imagination and character. It is possible to distinguish a number of support questions which will aid in making the optimum choice (Badaracco, 2016).

1) Do the goals interact with each other?

It is essential to study the correlations between ideas from goal trees. This has to be done in a way 

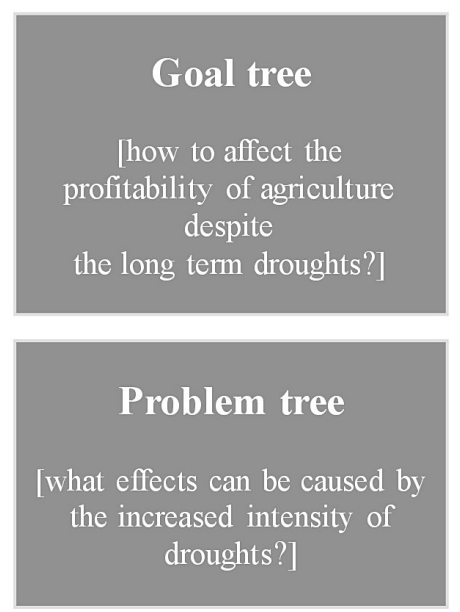
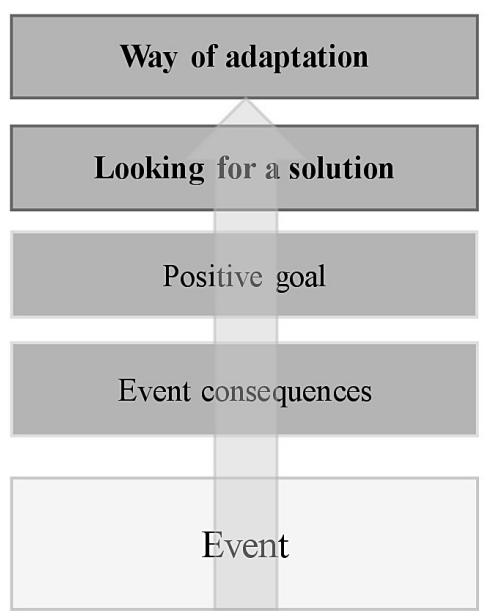

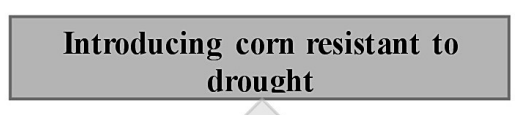

Change in crops

Agriculture provides profit

Agriculture does not provide profit

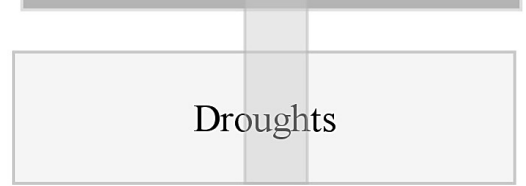

Figure 4. Problem tree and goal tree model using the prognostic method with an example [Trocki, 2012]

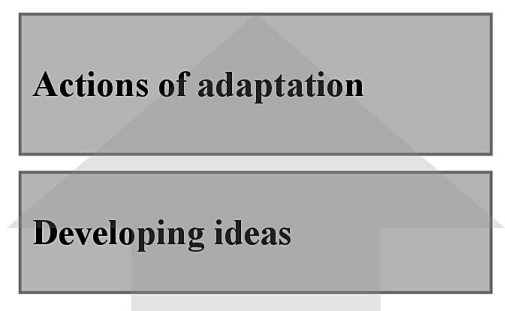

$$
\begin{aligned}
& \text { Relation between: } \\
& \text { opportunity and advantage }
\end{aligned}
$$

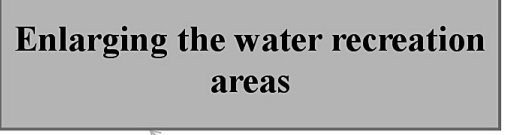

\section{Greater demand for services}

Heat waves and the advantage of water recreation areas

Figure 5. Goal tree model using the diagnostic method with an example [Trocki, 2012]

which ensures internal consistency with the rejection of mutually exclusive goals. The remaining goals are evaluated according to the force of their interaction using a four point scale: 0 (no correlation), 1, 2, and 3 (where there is a strong, complementary interaction). The analysis begins with a study of the way in which the goals impact each other. The sums of these values (the intensity sum and reactivity sum) are calculated accordingly.

The second step involves drawing intensity maps (Fig. 6) placing the intensity and reactivity sums for each goal on the chart. This is followed by the calculation of the average value of the intensity and reactivity sums, is also placed on the chart (in the below example it is marked using a gray diamond) and serves as the borderline for goal groups.

This technique allows for:

- identifying the interaction between goals

- making use of the synergy effect

- eliminating goals which hinder the realisation of other, higher-value goals

- ordering the goals in a hierarchy (Krawczyk and Bembenek, 2015)
2) What fundamental duties need to be fulfilled?

It is also useful to verify that no resolutions that are obligatory for the city have been eliminated. These include all legally required actions, as well as such whose lack may put the unit at risk of financial and material loss or may cause the deterioration or loss of the lives and health of its residents.

3) Can the goals be accomplished under current conditions?

When submitting possible solutions for the goal trees even the most uncertain answers which could potentially turn out the most beneficial have been taken into account. It is necessary to distinguish between those goals which are worth the effort from those that are bound to fail (Badaracco, 2016). Goals should comply with the SMART concept in order to maintain the highest chances for realisation (Conzemius and O’Neill, 2006).

4) Who are we and what goals do we wish to pursue?

The choice of goals should be compatible with one's own standards. In order to formulate such guidelines it may prove helpful to define 


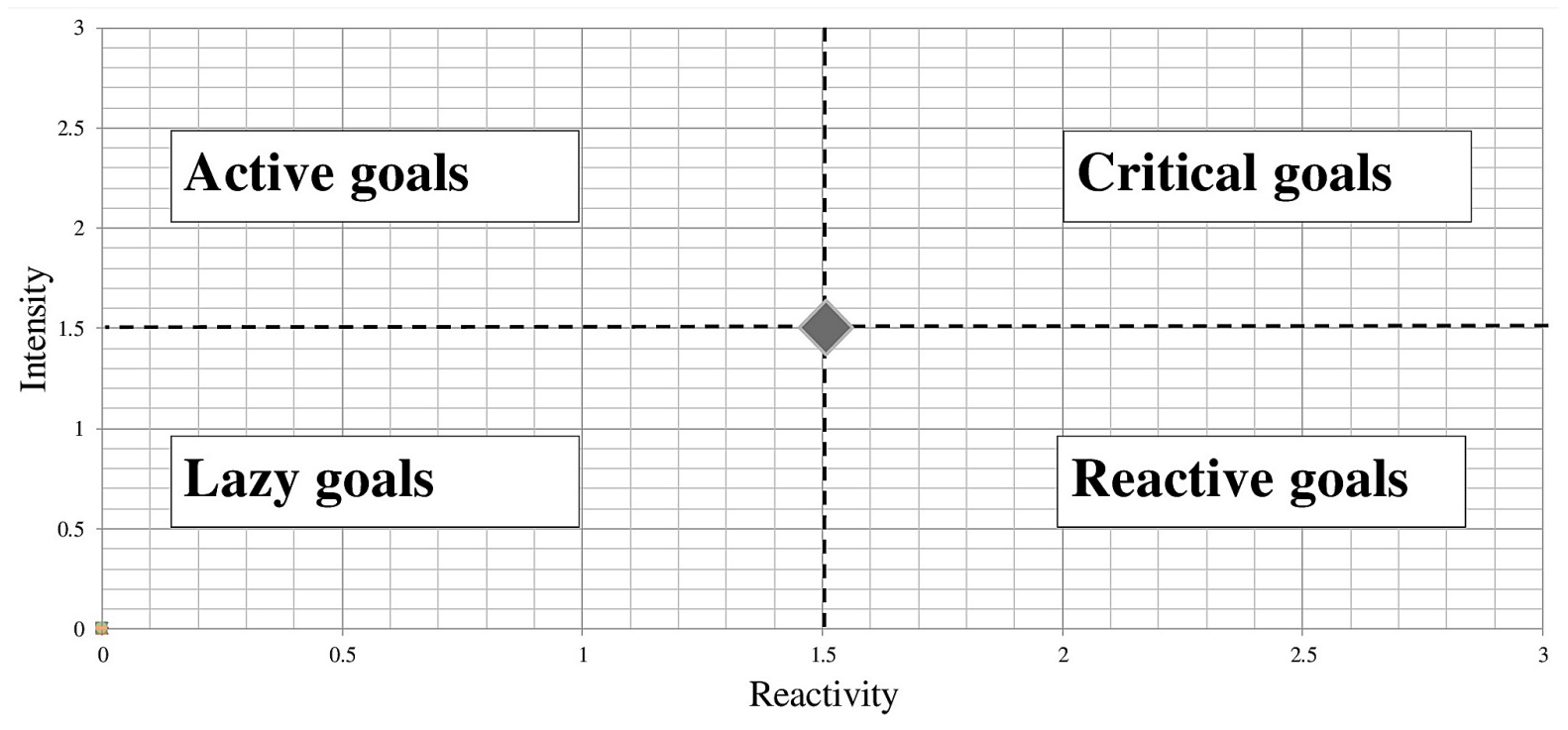

Figure 6. Goal intensity map [Krawczyk and Bembenek, 2015]

the mission of the unit. The Ashridge model, i.e. a complex instruction of creating the image of a unit through establishing its purpose, strategy, behaviour standards and values is the best choice for this task (Campbell, 1996).

5) Are the set goals compatible with the convictions of the decision-maker?

Good judgement is based on two components. The first one is the best possible understanding and analysis of the situation; the other involves the ideals and experience of the decision-making party. At times, despite having an objective approach to formulating resolutions it may prove difficult to follow them without compromising one's inner convictions (Badaracco, 2016).

When one is unsatisfied with the set of goals established as a result of previous analyses it may be helpful to consider whether the components have been revaluated or the calculations incorrect. If no technical fault is involved yet the issue remains unclear, the goals should be analysed with regard to the policy pursued up to that point. In the case of persisting inconsistencies the goal should be eliminated or the existing document updated.

All analyses and their results serve to support the decision-making process. They do not provide unquestionable answers, as point evaluations and result interpretation, despite being representative of the objective quantitative approach, are nevertheless conducted by people acting through the scope of their own opinions and experiences. Once the adaptation goals whose realisation will best serve the city are chosen, they need to be represented in the right hierarchy and with a sufficient level of detail. It is suggested to create a goal card and automatically assign values in accordance with the SMARTER (Specific, Measurable, Achievable, Relevant, Trackable, Exciting, Recorded) model.

\section{FORMULATING A STRATEGY}

All the lesser goals which have been selected as adequate for realisation in the process of climate change adaptation need to be represented in a systematic structure in accordance with the provisions of strategic documents. It is suggested to delineate two directions which will allow for a clear-cut division of strategic and operational goals.

\section{Building adaptive capacity}

Involves efforts aimed at preparation for climate change through formulating the necessary information, creating suitable legal regulations, preparing institutions and management for responsibility and the possibility of effective adaptation.

\section{Delivering adaptation action}

This direction involves the goals and actions of practical efforts decreasing the susceptibility to threats or utilising the opportunities from climate changes. Further set strategic and operational goals, as well as specific actions may significantly differ from each other-from easy solutions with a low degree of technical complexity to complicated projects (UKCIP, 2013) 


\section{CONCLUSIONS}

The method overview as well as the analyses detailed above allowed for the solution of two problems: the creative problem (the need to establish the structure of a new document [framework], by indicating the procedure model, coordinating actions undertaken by the local authority with regard to formulating project work, implementation, monitoring and evaluation of the document and the efforts of groups responsible for creating the UAP) and the optimisation problem (the solution to which allows to improve the utilised methods, techniques and tools - in this case through adjusting the methods and tools, which would lead to the formulation, enactment and implementation of UAP provisions in a most objective and successful manner).

Using the proposed methodic approach may prove helpful in the process of formulating and implementing UAPs in an ordered fashion. This will increase the efficiency of the unit's authorities and the parties responsible for task delivery stipulated in the UAP. It will also allow for consistent future evaluations of the character of the UAP and the progress in the gradual implementation of its goals. Another important aspect involves proposing specific methods, techniques and tools which will allow for conducting an evaluation of susceptibility and risk, as well as analyses of adaptation options in a way which will make it possible to choose the most objective form of establishing the directions for adaptation and adaptation goals.

The most significant stages of the process are arranged as follows: the PESTEL analysis in the form of the 635 technique has been suggested for the stage of data retrieval, as it will allow for the optimal use of social participation; the Delphi technique will make it possible to invite scientific circles into the process. Risk and susceptibility need to be determined through a diagnosis. The first is established using an analysis of the past, along with a quantitative evaluation of consequences occurring at that time. Susceptibility is determined using a matrix of relations between features and the consequences of climate change. What is most important at this stage is to specify priority threats (indicating the most dangerous results of climate change), as well as weaknesses (which may most profoundly exacerbate the threats) and strengths (which will aid in the most beneficial use of climate change results). The fac- tors with the highest priority will be used at further stages. The prognostic stage makes use of the forced association technique, specifically through the creation of goal trees, which make it easier to understand which actions towards adaptation have higher priority, allowing for the utilisation of opportunities and the prevention of threats. The final stage of the process of creating UAPs is the selection of the most important goals from the ones described above, with the help of support questions. A set of tools has also been proposed, including: the goal map, the SMART concept, and the Ashridge model of formulating one's mission. The selected goals need to be formulated in a coherent manner. This is made easier with the use of the complex SMARTER method in the form of a goal card. The resulting basis for action serves as a starting point for creating UAPs. The authors, however, are aware that certain problems requiring the modification of the method of formulating the UAP may emerge only in the course of conducting analyses of a specific case study. The proposed methodic approach to UAP formulation complies with the Adaptation manual for cities which testifies the utilitarian character of this article.

\section{REFERENCES}

1. Araos, M., Berrang-Ford, L., D. Ford, J., E. Austin, S., Biesbroek, R., Lesnikowski, A. 2016. Climate change adaptation planning in large cities: A systematic global assessment. Environ. Sci. Policy, 66, 375-382.

2. Badaracco, J.L., 2016. Managing yourself: How to tackle your toughest decisions. Harvard Business Review (September), 104-107.

3. Biniak-Pieróg M. 2014. Dynamics of water content in light bare soil in summer half-year in the period of 2003-2012 and its agro-meteorological determinants. Journal of Water and Land Development, 22, 41-50.

4. Campbell, A. 1996. Mission and management commitment. Ashridge Strategic Management Centre, London.

5. Conzemius, A., O’Neill, J. 2006. The Power of SMART Goals: Using Goals to Improve Student Learning. Solution Tree Press, Bloomington.

6. Foryś I., Putek-Szegląg E. 2014. Methods of linear ordering in estimation of potential of Polish market of agricultural property, Actual Problems of Economics, 151(1), 542-550.

7. Gober, P., A. Sampson, D., Quay, R., D. White, D., 
T.L. Chow, W. 2016. Urban adaptation to megadrought: Anticipatory water modeling, policy, and planning for the urban Southwest. Sustain. Cities Soc., 27, 497-504.

8. Kazak J., Malczyk J., Castro D. G., Szewrański S. 2016. Carbon sequestration in forest valuation, Real Estate Management and Valuation, 24(1), 76-86.

9. Kazak J., Świąder M., Szewrański S., Żmuda R. 2017. Geo-environmental indicators in Strategic Environmental Assessment, Acta Scientiarum Polonorum Formatio Circumiectus, 16(2), 123-135.

10. Kazak J., van Hoof J., Szewranski S. 2017. Challenges in the wind turbines location process in Central Europe - The use of spatial decision support systems, Renewable and Sustainable Energy Reviews, 76, 425-433.

11. Kemfert, C., 2005. Global Climate Protection - Immediate Action Will Avert High Costs (No. 12/2005). German Institute for Economic Research (DIW Berlin), Berlin.

12. Krawczyk, B., Bembenek, M. 2015. Goal intensity map. Management Encyclopedia. https://mfiles. $\mathrm{pl} / \mathrm{pl} /$ index.php/Mapa_intensywno\%C5\%9Bci_ cel\%C3\%B3w (access date: 09.09.2016) (in Polish).

13. Kundzewicz, Z., 2013. A warmer climate. A thing about climate change. PWN Scintific Publishing House, Warsaw (in Polish).

14. Kurek, K., 2011. Climate change. Centro Editor PDA, S.L., Warsaw (in Polish).

15. Leszczyńska, A., 2013. Strategies of Polish enterprises in the face of climate challenges. UMCS, Lublin (in Polish).

16. Litewka, A., 2010. Strategic foresight. Management Encyclopedia. https://mfiles.pl/pl/index.php/ Foresight_strategiczny (access date: 09.09.2016) (in Polish).

17. Ministry of the Environment. 2013. Polish National Strategy for Adaptation to Climate Change (NAS 2020) with the perspective by 2030.

18. Ministry of the Environment. 2014. The adaptation guide for cities. Guidelines for preparing the Urban Adaptation Plan for climate change (in Polish).

19. Molasy, M. 2016. Organizational methods and techniques in management.

20. Obłój, K. 2001. Organization strategy. In search of a lasting competitive advantage. Polish Economic Publishing House, Warsaw (in Polish).

21. Olszewska B., Nowicka E. 2015. Comparison of gravimetric method and TDR method applied to medium alluvial soils of the valley of the Oder river in the region of Brzeg Dolny in the period of 2010-2014, Journal of Ecological Engineering, 16(4), 44-48.

22. Pasik M., Woźniak, K. Check-list. Management Encyclopedia, https://mfiles.pl/pl/index.php/
Check-lista (access date: 09.09.2016.) (in Polish)

23. Pawęska K., Bawiec A. 2017, Activated sludge technology combined with hydroponic lagoon as a technology suitable for treatment of wastewater delivered by slurry tanks, Journal of Ecological Engineering, 18(2), 29-37.

24. Przybyła, K., Kulczyk-Dynowska, A., Kachniarz, M. 2014. Quality of life in the regional capitals of Poland, Journal of Economic Issues, 48(1), 181-196.

25. Przybyło, J. 2011. The 635 technique. Management Encyclopedia. https://mfiles.pl/pl/index.php/Technika_635 (access date: 09.09.2016) (in Polish).

26. Sarzynski, A. 2015. Public participation, civic capacity, and climate change adaptation in cities. Urban Clim., 52-67.

27. Świąder M., Tokarczyk-Dorociak K., Szewrański S., Kazak J. 2016. Analysis of Regional Operational Programmes for the 2014-2020 period in the context of financing the Renewable Energy Investments, Energy Market, 124(3), 72-80 (in Polish).

28. Szewrański S., Kazak J., Sylla M., Świąder M. 2017. Spatial data analysis with the use of ArcGIS and Tableau systems, Lecture Notes in Geoinformation and Cartography, Volume Part F3, 2017, 337-349.

29. Szewrański S., Kazak J., Żmuda R., Wawer R. 2017. Indicator-based assessment for soil resource management in the Wrocław larger urban zone of Poland, Polish Journal of Environmental Studies, 26(5), 2239-2248.

30. Team FME, 2013. PESTLE Analysis. Strategy Skills. www.free-management-ebooks.com.

31. Tokarczyk-Dorociak K., Walter E., Kobierska K., Kołodyński R. 2017. Rainwater Management in the Urban Landscape of Wroclaw in Terms of Adaptation to Climate Changes, Journal of Ecological Engineering, 18(6), 171-184.

32. Trocki, M. 2012. Modern project management. Polish Economic Publishing House, Warsaw.

33. UKCIP. 2013. UKCIP Adaptation Wizard. UKCIP.

34. van de Ven F.H.M., Snep, R.P.H., Koole, S., Brolsma, R., van der Brugge, R., Spijker, J., Vergroesen, T. 2016. Adaptation Planning Support Toolbox: Measurable performance information based tools for co-creation of resilient, ecosystem-based urban plans with urban designers, decision-makers and stakeholders. Environ. Sci. Policy, 66, 427-436.

35. Voros, J. 2003. A generic foresight process framework. Foresight, 5(3), 10-21.

36. Walsh, J., Wuebbles, D. et al. 2014. Our Changing Climate. Climate Change Impacts in the United States: The Third National Climate Assessment (Mellilo J.M., Richmond T.(TC), Yohe G.W., Eds.), U.S. Global Change Research Program, 19-67. 